This is an Accepted Manuscript of an article published by Taylor \& Francis in 'The Journal of Educational Research' on 2018-05-08, available online:

https://www.tandfonline.com/10.1080/00220671.2018.1448749.

\title{
Evaluating the effectiveness of a mindfulness coloring activity for test anxiety in children
}

\section{ABSTRACT}

The authors investigated the effectiveness of a mindfulness art activity compared with a free draw/coloring activity on test anxiety in children. The sample consisted of 152 students (50\% female; $M_{\text {age }}=10.38$ years, $S D=0.88$ years) randomly assigned to a mindful $(n=76)$ or free $(n=76)$ group. Participants completed a standardized measure of anxiety and state mindfulness before and after the coloring activity, immediately before a spelling test, as well as a measure of dispositional mindfulness. Results revealed an overall significant decrease in test anxiety and an overall significant increase in state mindfulness following the interventions. Furthermore, although a significant negative correlation was found between dispositional mindfulness and change in state mindfulness pre- and post-coloring intervention, a significant positive correlation was found between dispositional mindfulness and pre-intervention state mindfulness, suggesting a possible ceiling effect. Explanations for these findings and implications for school personnel and future research are discussed.

Test anxiety, an individual's reaction to test taking, is experienced by approximately one third of elementary school students (Dan \& Raz, 2015; Lowe \& Lee, 2008; Whitaker Sena, Lowe, \& Lee, 2007) and is considered to be the most prevalent form of anxiety in schools (Lohbeck, Nitkowski, \& Petermann, 2016). Test anxiety increases from childhood to adolescence (McDonald, 2001) and although there has been a rise in test anxiety interventions for youth, these programs are typically lengthy and include several sessions that span over multiple weeks (e.g., Bradley et al., 2010; Gregor, 2005; Larson, Ramahi, Conn, Estes, \& Ghibellini, 2010; Weems et al., 2009; Yahav \& Cohen, 2008). School-based programs that 
This is an Accepted Manuscript of an article published by Taylor \& Francis in 'The Journal of Educational Research' on 2018-05-08, available online:

https://www.tandfonline.com/10.1080/00220671.2018.1448749.

require a great deal of time are difficult to implement and are not likely to be chosen and accepted by schools (Bishop, Bryant, Giles, Hansen, \& Dusenbury, 2006; Fridrici \& Lohaus, 2009). As such, it is critical to implement simple and effective test anxiety interventions to easily incorporate in schools. Mindfulness, the act of nonjudgmentally and purposefully paying attention to and being aware of present moment experiences (Kabat-Zinn, 2003), has been suggested as a helpful classroom approach to address generalized anxiety and test anxiety in children (Burke, 2010; Napoli, Krech, \& Holley, 2005). Mindful art making, which has been receiving increasing attention in the literature and throughout popular culture, is an example of a brief, simple mindfulness activity that is easy to implement in the classroom setting, as it requires no additional teacher training and minimal class time (Carsley, Heath, \& Fajnerova, 2015). Given the need for brief test anxiety interventions for children and the limited teacher and school requirements associated with a mindfulness-based art activity, the purpose of this study was to examine the effectiveness of a brief mindfulness-based coloring intervention for decreasing test anxiety in elementary school students.

\section{Test anxiety}

Test anxiety is regarded as both a state of anxiety—-the perceived threat before the testor trait related; the general and continuous worry of performance evaluation (Lowe et al., 2008). As such, test anxiety has been suggested to occur along a continuum, and rather than some individuals indicating that test anxiety is always present, students may differ in their experiences of test anxiety (McDonald, 2001). Test anxiety is associated with a number of negative outcomes such as overanxious disorder and other types of anxiety disorders (e.g., social phobia), and mental health difficulties (e.g., specific phobia, depression; King, Mietz, Tinney, \& Ollendick, 
This is an Accepted Manuscript of an article published by Taylor \& Francis in 'The Journal of Educational Research' on 2018-05-08, available online:

https://www.tandfonline.com/10.1080/00220671.2018.1448749.

1995; LeBeau et al., 2010), low self-esteem (Pekrun, 2000), lower grades and academic performance (Eum \& Rice, 2011; Segool, Carlson, Goforth, Von der Embse, \& Barterian, 2013), grade retention (Hembree, 1988), and dropout (Chapell et al., 2005; Tobias, 1979). Furthermore, effects of test anxiety can increase in severity if not treated at a young age (Swanson \& Howell, 1996). Due to the rise in testing requirements in schools, the number of students reporting test anxiety is expected to escalate as well (Lowe, Grumbein, \& Raad, 2011; Wren \& Benson, 2004). To limit these negative associations and the potential increases in the prevalence of test anxiety as students progress from elementary school to high school and higher education, it is critical to identify and implement effective test anxiety reduction and/or prevention programs for children within elementary school (Ergene, 2003; Von der Embse, Barterian, \& Segool, 2013).

There has been a growing interest in determining the effectiveness of test anxiety interventions; however, many of the existing test anxiety interventions are created for students in higher education, rather than children. Test anxiety interventions with youth should be delivered as universal school-based interventions (Weems et al., 2010) as the school provides access to a large group of students, and students with test anxiety will not feel singled out.

\section{Mindfulness}

Over the past decade, there has been a considerable increase in mindfulness interventions to support children in managing state and trait generalized anxiety, and most recently, test anxiety, through school and classroom-based approaches (e.g., Carsley et al., 2015; Napoli et al., 2005; Zenner, Herrnleben-Kurz, \& Walach, 2015). Similar to anxiety, mindfulness can be regarded as both a state (the experiencing of mindfulness at a particular moment in time) and an individual disposition (the general experiencing of mindfulness day-to-day). Specifically, states 
This is an Accepted Manuscript of an article published by Taylor \& Francis in 'The Journal of Educational Research' on 2018-05-08, available online:

https://www.tandfonline.com/10.1080/00220671.2018.1448749.

of mindfulness have been found to increase following interventions (Burke, 2010) and variations in dispositional mindfulness may occur naturally or may be enriched through mindfulness practice. Dispositional mindfulness can contribute to psychological well-being outcomes associated with mindfulness interventions, and the more frequent experiencing of a mindfulness state following an intervention has been associated with greater levels of dispositional mindfulness over time (Kiken, Garland, Bluth, Palsson, \& Gaylord, 2015; Shapiro, Oman, Thoresen, Plante, \& Flinders, 2008). In addition, higher levels of mindfulness have been shown to be associated with lower levels of test anxiety in a number of studies (Cunha \& Paiva, 2012; Napoli et al., 2005); therefore, it would be important to examine the role of dispositional mindfulness during a mindfulness-based intervention for test anxiety in children, in addition to the effect of the actual mindfulness intervention or activity.

\section{Mindfulness coloring}

A brief and easy-to-implement mindfulness activity that has emerged in education research and throughout popular media is mindful art making (e.g., Beckwith, 2014; Callahan, 2016; Carsley et al., 2015). Mindful art making is hypothesized to combine the creative manipulation of materials found in art making (e.g., Abbott, Shanahan, \& Neufeld, 2013) with the benefits of mindfulness meditation (Curry \& Kasser, 2005). Within the past couple of years, mindfulness-based coloring activities, such as structured coloring of mandalas, have been incorporated into the school, home, and work environments for test anxiety, anxiety, and stress reduction; however, empirical support for the benefits of this activity is limited and the findings are mixed (Carsley et al., 2015; Curry \& Kasser, 2005; Van der Vennet \& Serice, 2012). These coloring activities are considered to be mindfulness based because individuals have been shown 
This is an Accepted Manuscript of an article published by Taylor \& Francis in 'The Journal of Educational Research' on 2018-05-08, available online:

https://www.tandfonline.com/10.1080/00220671.2018.1448749.

to remain focused and aware of present moment experiences while coloring (Barrett, 2015).

Specifically, structured mandalas_-which are circular designs composed of symmetrical shapes—-facilitate in-depth attention and engagement inherent to mindfulness activities and are believed to create a state of mindfulness (Carsley et al., 2015; Curry \& Kasser, 2005; Henderson, Rosen, \& Mascaro, 2007). Unlike free drawing and coloring, filling in the intricate shapes and repeating patterns of the mandala provides individuals with the opportunity to experience a state of focused awareness, which has also been found in other forms of meditation (Curry \& Kasser, 2005). The combination of the structure associated with coloring in a mandala and the complexity of the design has been suggested to provide participants with a sense of direction when coloring and in organizing their experience. The lack of structure individuals feel during a free coloring activity may be challenging, and perhaps even anxiety inducing, as they feel the need to create their own structure (Curry \& Kasser, 2005).

The benefit of structured mandala coloring on anxiety reduction compared with free coloring and structured plaid forms pre- and post-coloring activity have been repeatedly demonstrated in university samples (Curry \& Kasser, 2005; Van der Vennet \& Serice, 2012). This structured mindfulness approach has been incorporated in elementary educational settings, but there is limited research conducted on the test anxiety benefits of this activity in childhood. Given that mindfulness-based coloring is consistently promoted as antistress and antianxiety activities in the media, more empirical research is required to determine the effectiveness of these particular mindfulness approaches in children.

To empirically evaluate whether elementary school students benefit in terms of test anxiety reduction from this mindfulness-based art making activity, Carsley et al. (2015) 
This is an Accepted Manuscript of an article published by Taylor \& Francis in 'The Journal of Educational Research' on 2018-05-08, available online:

https://www.tandfonline.com/10.1080/00220671.2018.1448749.

conducted the first study examining the effectiveness of mindfulness-based (mandala) structured coloring versus free unstructured coloring on test anxiety in children. Participants in Grades 4 to $6(53.8 \%$ female $)$ were randomly assigned to either a structured mindfulness $(n=26)$ or unstructured free coloring condition $(n=26)$, matched for gender. A spelling test was used to elicit participants' test anxiety, and students completed the State-Trait Anxiety Inventory for Children state form (STAIC-S) to assess anxiety before and after coloring. A significant overall decrease in test anxiety for both groups was found; however, a significant gender by group interaction demonstrated that while both genders experienced test anxiety reduction in the mindfulness coloring condition, boys reported a greater test anxiety reduction in the free coloring condition whereas girls in the free condition did not report this change.

These results are partially inconsistent with previous university studies that did not examine gender differences in their research, and found that coloring structured mandalas is associated with greater decreases in anxiety compared with a free coloring activity (Curry \& Kasser, 2005; Van der Vennet \& Serice, 2005). One explanation for the gender difference found in Carsley et al.'s (2015) study could be due to developmental differences in this elementary study compared with the university studies. It is typical for boys' fine motor development to be slower than girls' (Hanlon, Thatcher, \& Cline, 2000; Kail \& Cavanaugh, 2015), which could suggest that coloring the small shapes in the mandala are more challenging than free coloring for boys (Carsley et al., 2015). A second explanation could be that girls at this developmental stage are more prone to benefiting from a mindfulness structured art activity due to a greater tendency to experience mindfulness, yet this has not been examined. A third explanation could be that young children might report free draw/coloring to be a mindfulness-based activity. Unlike the university studies, both groups in Carsley et al.'s study reported decreases in test anxiety 
This is an Accepted Manuscript of an article published by Taylor \& Francis in 'The Journal of Educational Research' on 2018-05-08, available online:

https://www.tandfonline.com/10.1080/00220671.2018.1448749.

following the coloring activities; therefore, it is important to assess if they are reporting increases in mindfulness states as well. Although coloring in the complex shapes of structured mandalas has been identified as an art making activity that creates an attentive and mindfulness-type state (Beckwith, 2014), an examination of the effectiveness of these specific activities on mindfulness states is required to determine if free coloring can also be considered as a mindfulness-based activity.

As mentioned previously, it is also possible that some students might experience greater dispositional mindfulness, which can influence their experiencing of mindfulness states. Specifically, the benefits of this state mindfulness intervention may differ depending on an individual's dispositional mindfulness; therefore, it is important to determine whether the gender differences that were found are related to participants' dispositional mindfulness. The majority of studies examining the relation between gender and dispositional mindfulness have not found significant gender differences (e.g., Shapiro, Brown, \& Biegel, 2007; Shorey, Anderson, Lookatch, Morre, \& Stuart, 2014; Tan \& Martin, 2012); yet, this absence of findings may be due to predominantly male or female samples of participants (e.g., Beauchemin, Hutchins, \& Patterson, 2008; Biegel, Brown, Shapiro, \& Schubert, 2009; Broderick \& Metz, 2009). There is a need for further research to clarify and explain the dispositional mindfulness benefits of these approaches.

\section{Summary}

Given the preliminary evidence that male and female elementary school children respond differently to mindful art making (Carsley et al., 2015), an examination of the consistency of these findings, as well as an elaboration on possible factors (e.g., state mindfulness, dispositional 
This is an Accepted Manuscript of an article published by Taylor \& Francis in 'The Journal of Educational Research' on 2018-05-08, available online:

https://www.tandfonline.com/10.1080/00220671.2018.1448749.

mindfulness, gender) that contribute to the effectiveness of this activity for children is required. Specifically, (a) is a mindfulness-based coloring activity effective in reducing test anxiety in children compared with a free coloring activity, and (b) do students' self-reported mindfulness and gender contribute to these changes in test anxiety? The purpose of this study was to examine the effectiveness of a mindfulness-based art making activity for test anxiety in elementary school students. Specifically, the first objective is to test the effectiveness of a mindfulness coloring activity on reducing test anxiety and increasing state mindfulness in children before a test, compared with a control group participating in a free draw/coloring activity. It was hypothesized that participants would experience overall test anxiety reduction (Hypothesis 1) and increases in state mindfulness (Hypothesis 2) in both the mindfulness and free coloring conditions; however, boys would report a greater test anxiety reduction (Hypothesis 3 ) and greater increase in state mindfulness in the free coloring condition (Hypothesis 4) whereas girls would only benefit from the mindfulness coloring condition. Building on these hypotheses, the second objective assessed the relation between dispositional mindfulness and students' experiencing of changes in state mindfulness following the intervention, with an examination of gender differences. Due to the absence of reported gender differences in dispositional mindfulness research with children, no specific hypotheses were proposed.

\section{Methods}

\section{Participants}

Participants were 154 students (49.4\% female) in Grades 4, 5, and 6 from public co-ed elementary schools in Montreal, Quebec, Canada. The majority of students from these schools were Caucasian, from middle- and upper-class families with English as their primary language. 
This is an Accepted Manuscript of an article published by Taylor \& Francis in 'The Journal of Educational Research' on 2018-05-08, available online:

https://www.tandfonline.com/10.1080/00220671.2018.1448749.

All schools offer French immersion programs and students receive 70-80\% of instruction in

French from Kindergarten to Grade 2, and 50\% of instruction in English and 50\% in French from

Grade 3 onward. As indicated in the Procedure section, participants completed the spelling section of the Wide Range Achievement Test, a standardized norm-referenced brief measure of fundamental academic skills (WRAT-4; Wilkinson \& Robertson, 2006); overall, students' scores were average with a standard average mean score of $108.63(S D=11.56)$.

Following approval from the school board and the governing board of the individual schools, parents of the students were required to provide consent for their children to participate in the study. To ensure that all students received the same information, an oral script that described the present study was read to the students. Following this description, 241 consent forms were distributed to students to take home to their parents. Only those agreeing to participate returned the forms. Given the time constraints of the school, students were required to return their signed consent forms within one week of the date in which the forms were distributed. A total of 165 approved consent forms were received (68\% consent); 11 students were absent on the days when the interventions were scheduled at their school and were not able to participate. In addition, two participants were found to be multivariate outliers and were therefore removed from analyses; thus, the final sample consisted of 152 students (50\% female; $M_{\mathrm{age}}=10.38$ years, $S D=0.88$ years), 76 participants in the free group and 76 participants in the mindful group, matched for gender.

\section{Measures}

\section{STAIC-S}


This is an Accepted Manuscript of an article published by Taylor \& Francis in 'The Journal of Educational Research' on 2018-05-08, available online:

https://www.tandfonline.com/10.1080/00220671.2018.1448749.

The STAIC-S is a widely used self-report measure that assesses children's current state of anxiety (Nilsson, Buchholz, \& Thunberg, 2012). The STAIC-S contains 20 items and takes 5-10 minutes to complete. Children are asked to indicate the way they feel at the exact moment. Each item on the questionnaire begins with the statement "I feel..." and participants indicate their current state by circling one of the three given options (e.g., "I feel...very nervous/nervous/not nervous," "I feel...very jittery/jittery/not jittery"). The STAIC-S, developed from Spielberger's State-Trait Anxiety Inventory for Children (STAI-C), was the only subscale included in this study, and it has been associated with high internal consistency (.82-.87; Myers \& Winters, 2002; Spielberger, 1973) and moderate test-retest reliability (.31-.47; Spielberger, 1973). In the present study, Cronbach's alphas ranged from .86 to .90 pre- and post-intervention, with a testretest correlation of .65. Spielberger assessed predictive validity by comparing participants' scores in a test condition (in which participants were asked to respond to the items according to how they would feel before a final examination) with participants' scores in a norm condition. Results revealed that compared with scores in the norm condition, scores in the test condition were significantly higher for all items.

\section{Mindful attention awareness scale, state version}

The Mindful Attention Awareness Scale state version (state MAAS) was developed from the original Mindful Attention Awareness Scale and measures an individual's current state of mindfulness (Brown \& Ryan, 2003). The state MAAS is a validated measure of state mindfulness, and it includes 5 items adapted from the original MAAS, such as "I'm finding it difficult to stay focused on what is happening right now." Using a 7-point Likert-type scale ranging from 0 (not at all) to 6 (very much), individuals indicate how they are feeling in that 
This is an Accepted Manuscript of an article published by Taylor \& Francis in 'The Journal of Educational Research' on 2018-05-08, available online:

https://www.tandfonline.com/10.1080/00220671.2018.1448749.

particular moment. Once the data was entered for this measure, scores were reversed so that higher scores on the state MAAS were indicative of higher state mindfulness. The state MAAS has been shown to have high internal consistency (Cronbach's $\alpha=.92$ ), and a predictive relation with dispositional mindfulness as measured by the MAAS (Brown \& Ryan, 2003). In the present study, Cronbach alphas ranged from .71 to .72 pre- and post-intervention, with a test-retest correlation of .66. The original version of the state MAAS contains items focusing on a past state-mindfulness experience (e.g., "I was doing something without paying attention"). To assess current and immediate experiences of mindfulness before and after the intervention, the items in this study have been adapted to show this change (e.g., "Right now, I am doing this without really paying attention)."

\section{Child and adolescent mindfulness measure}

The Child and Adolescent Mindfulness Measure (CAMM) is a self-report measure of dispositional mindfulness (Greco, Baer, \& Smith, 2011). This measure consists of 10 reversescored items about children's and adolescents' self-reports of mindfulness that focus on present

moment awareness (e.g., "I think about things that happened in the past instead of thinking about things that are happening right now") as well as nonjudgmental acceptance (e.g., "I tell myself that I shouldn't feel the way I'm feeling"). Participants indicate how often an item is true for them on a 5-point Likert-type scale ranging from 0 (never true) to 4 (always true). The CAMM has adequate internal consistency and divergent validity with measures of thought suppression and psychological inflexibility (Greco et al., 2011). In the present study, the CAMM was shown to have a Cronbach's alpha of .72 .

\section{Procedure}


This is an Accepted Manuscript of an article published by Taylor \& Francis in 'The Journal of Educational Research' on 2018-05-08, available online:

https://www.tandfonline.com/10.1080/00220671.2018.1448749.

In groups of 8-27, participants either arrived to a central location to complete the study, or the researcher and her assistants entered their current classroom. Students were randomly assigned to an intervention group or control group. Participants were provided with an envelope that contained all of the measures, and either a structured mandala or blank sheet of paper; to ensure that the distribution of envelopes was completely random, the contents of the envelope were only visible once students opened the envelopes. To elicit test anxiety, students were told that the results of their spelling test would be given to their parents after they finished the test. This method was used in a previous study, and has been found to be an effective method for eliciting test anxiety (Carsley et al., 2015).

Immediately before the intervention, the students completed the STAIC-S and the state MAAS. The researcher read through each item on the measures with the students to ensure that the students understood all of the questions. Students were told to respond to questions as honestly as possible. Once these measures were completed, the intervention group was given colored pencils to color the same predesigned mandalas, while the control group was provided with colored pencils to draw and color on their blank sheet of paper. The intervention and control condition colored on their respective papers for $15 \mathrm{~min}$, after which both conditions completed the same test anxiety measure as a posttest to assess test anxiety levels, and the same state mindfulness measure to assess their state of mindfulness postintervention. Similar to the pretest, the researcher read through the measures with the students to make sure that the students understood all of the items.

Following the posttest assessments, the students were given the spelling section of the WRAT-4. The researcher read through the instructions with the students and the students were 
This is an Accepted Manuscript of an article published by Taylor \& Francis in 'The Journal of Educational Research' on 2018-05-08, available online:

https://www.tandfonline.com/10.1080/00220671.2018.1448749.

given 15 minutes to complete the test. All students then completed the CAMM to assess their dispositional mindfulness. Students were then debriefed on the purpose of the study and received a debriefing sheet to take home to their parents. All participants received a list of resources and suggestions for managing anxiety and for literacy and writing development. The school was provided with summarized group scores for the spelling test and test anxiety questionnaire, and each student's spelling and test anxiety score was summarized and given to their parents.

\section{Results}

All data were analyzed with SPSS version 20. There were a total of 17 missing values in the dataset due to incomplete questionnaires, and examination of missing data items revealed that all variables had less than 5\% of missing values. To maintain the sample size within each group, the estimation maximization procedure was performed to impute the missing data. There were five univariate and two multivariate outliers identified in the dataset; there was one univariate outlier for each of the pre and post measures, and they were all transformed to values that were one-unit higher or lower than the next highest or lowest value that was not an identified outlier (Tabachnick \& Fidell, 2007), and the multivariate outliers were removed from any further analyses.

Before running analyses, all relevant assumptions were checked and verified. The mindful group and free group were not significantly different according to their age, preintervention test anxiety, and pre-intervention state mindfulness scores (see Table 1); as a result, these variables were not considered in further analyses. 
This is an Accepted Manuscript of an article published by Taylor \& Francis in 'The Journal of Educational Research' on 2018-05-08, available online:

https://www.tandfonline.com/10.1080/00220671.2018.1448749.

Only significant results will be reported for the following main analyses. The first objective was to assess the effectiveness of a mindfulness coloring activity compared with a free draw/coloring activity on test anxiety and state mindfulness, as well as possible gender and group effects. Before conducting the main analysis, correlations were examined between the two dependent variables: post-intervention test anxiety and post-intervention state mindfulness. Results revealed a significant negative correlation between these two variables $(r=-.48, \mathrm{p}<$ .01). Based on the high intercorrelation, post-intervention test anxiety and state mindfulness were considered simultaneously in the following analysis. A repeated measures multivariate analysis of variance was conducted to test the effect of the coloring activities and gender on postintervention test anxiety and state mindfulness scores. Time (preintervention and postintervention) and test (test anxiety and state mindfulness) were entered into the repeated measures analyses. Results revealed a significant main effect for time, $F(1,148)=28.41, p<$ .001 , Wilk's $\lambda=.839$, partial $\eta^{2}=.161$. Furthermore, a significant two-way interaction was found between time (pre- to post-intervention) and test (test anxiety and state mindfulness), $F(1$, $148)=34.07, p<.001$, Wilk's $\lambda=.813$, partial $\eta^{2}=.187$ (see Table 2$)$.

Post hoc analyses were conducted to determine the specific effects of test anxiety and state mindfulness pre- and post-intervention. Results from two separate repeated measures analyses of variance revealed a significant difference in test anxiety pre- and post-intervention, $F(1,148)=32.07, p<.001$, Wilk's $\lambda=.822$, partial $\eta^{2}=.178$, and a significant difference in state mindfulness pre- and post-intervention, $F(1,148)=13.56, p<.05$, Wilk's $\lambda=.916$, partial $\eta^{2}=.084$. Examination of the means revealed that test anxiety scores decreased and state mindfulness scores increased pre- and post-intervention (see Tables 2 and 3), and no significant gender differences were uncovered. 
This is an Accepted Manuscript of an article published by Taylor \& Francis in 'The Journal of Educational Research' on 2018-05-08, available online:

https://www.tandfonline.com/10.1080/00220671.2018.1448749.

To assess the relations between dispositional mindfulness, changes in states of mindfulness from pre- to post-intervention, and gender, a series of steps were taken. First, a change in state mindfulness score was computed to determine if there was a gain in mindfulness states from pre- to postcoloring intervention. Second, bivariate and point biserial correlations were conducted to examine the relation among dispositional mindfulness, gender, and change in state mindfulness from pre- to postcoloring intervention. As demonstrated in the correlation matrix (see Table 4), the relations between (a) gender and dispositional mindfulness and (b) gender and change scores were not statistically significant. Due to the lack of significance regarding gender throughout the results, gender was no longer included in subsequent analyses in to order have the most parsimonious model possible.

A significant negative correlation between dispositional mindfulness and changes in state mindfulness was found $(r=-.21, p<.01)$, with high levels of dispositional mindfulness associated with lower changes in state mindfulness. An additional correlation analysis was then conducted to examine the association between dispositional mindfulness and preintervention state mindfulness, and a significant moderate positive correlation was found $(r=.50, p<.01)$. As demonstrated in Figure 1, the highest dispositional mindfulness score was associated with the highest possible preintervention state mindfulness scores, suggesting a possible ceiling effect.

\section{Discussion}

The purpose of this study was to assess the effectiveness of a mindfulness-based structured coloring activity for test anxiety in elementary school students. Specifically, the aims of this study were to (a) test the effectiveness of a structured coloring activity on test anxiety and state mindfulness in children compared with a free draw/coloring activity and (b) examine the 
This is an Accepted Manuscript of an article published by Taylor \& Francis in 'The Journal of Educational Research' on 2018-05-08, available online:

https://www.tandfonline.com/10.1080/00220671.2018.1448749.

role of dispositional mindfulness and gender in relation to students' experiencing of mindfulness states.

The first objective of this study was to examine the effectiveness of this mindfulnessbased art activity on children's test anxiety and state mindfulness. Consistent with previous studies (Carsley et al., 2015), participants in both the mindful and free conditions reported significant reductions in test anxiety from pre- to post-intervention; however, unlike previous research, a gender difference was not found. The present findings suggest that both boys and girls benefitted in terms of test anxiety reduction following both of the coloring activities. Unlike the university studies, which demonstrated a greater decrease in anxiety for students coloring in the mandala compared with free draw/coloring (Curry \& Kasser, 2005; Van der Vennet \& Serice, 2012), these findings may indicate that although the mandala can be an effective coloring activity for decreasing test anxiety, free draw/coloring is equally beneficial for test anxiety reduction. Although there is a possibility that the decreases in reports of test anxiety that were found for both conditions may reflect a decrease due to the repetition of completing the measure, if replicated, these findings are important as many educators are including mandalas in their classrooms for this purpose (Carsley et al., 2015); however, these results suggest that it may be equally helpful to incorporate other coloring activities as well to provide students with more options for experiencing the associated benefits.

The unexpected finding that boys and girls did not show a test anxiety difference following the mindful versus free coloring intervention in the present study may be a result of the way participants approached the tasks in the present study relative to Carsley et al.'s (2015) study. Specifically, Carsley et al. noted that a number of the male participants colored over the 
This is an Accepted Manuscript of an article published by Taylor \& Francis in 'The Journal of Educational Research' on 2018-05-08, available online:

https://www.tandfonline.com/10.1080/00220671.2018.1448749.

mandalas and did not attempt to color in the intricate shapes; examination of the materials from the present study revealed that all participants randomly assigned to the mindful condition attempted to color in the shapes rather than scribbling over the entire design. It is possible that boys and girls may be benefitting equally from both activities in the present study because they completed them in a similar way; however, in light of these contradictory findings, further research is needed to determine potential gender differences at this age.

In addition, an increase of mandala use or awareness in popular culture has since emerged following the first study conducted in elementary settings. When Carsley et al. (2015) examined the effectiveness of coloring mandalas versus free draw/coloring, coloring of structured mandalas was largely unfamiliar to the participating students. More recently, coloring of structured mandalas has been promoted throughout popular culture as a mindfulness-based antianxiety coloring activity, and many schools are now incorporating this activity within their classrooms. Qualitative examination of the coloring activities in the present sample revealed that a number of girls in the free condition were creating their own mandalas; therefore, the lack of gender difference in the free condition in this sample may be due to girls approaching the free coloring as a mandala, and benefitting accordingly. Further research is needed to evaluate these potential explanations.

Although both the mindful group and free group demonstrated significant increases in state mindfulness pre- and post-intervention, similar to the previous findings, there was no gender or group effect. This finding may be explained by considering that the definition of what constitutes a mindfulness-based activity may depend on how the individual approaches the mindfulness activity (Carsley et al., 2015). A mindfulness activity or practice has been described 
This is an Accepted Manuscript of an article published by Taylor \& Francis in 'The Journal of Educational Research' on 2018-05-08, available online:

https://www.tandfonline.com/10.1080/00220671.2018.1448749.

as consisting of some type of structure to control one's physical or mental activity (Greenberg \& Harris, 2012). This description would help explain why a structured mandala would be considered a mindfulness activity; however, it is also possible that participants' perception of a mindfulness activity may have an effect on their ability to focus and pay attention to what they are experiencing in that moment. In future studies, participants should be asked to report whether they "like" or "enjoy" participating in the activity, as their personal preference may influence their ability or motivation to remain focused in the present moment.

The second objective was to examine the relations between dispositional mindfulness, changes in states of mindfulness pre- and post-intervention, and gender. Individuals with higher dispositional mindfulness are likely to experience increases in mindfulness following an intervention (Shapiro, Brown, Thoresen, \& Plante, 2011); however, the finding that a negative relation was found between dispositional mindfulness and changes in state mindfulness suggested the opposite for the present sample. Therefore, an in-depth examination of state mindfulness in relation to participants' dispositional mindfulness was required.

The correlation and ceiling effect found between dispositional mindfulness and preintervention state mindfulness provided more information as to why this change score was not an accurate representation of state mindfulness. The highest dispositional mindfulness scores were found to be associated with the highest possible preintervention state mindfulness scores; thus, it was not possible to accurately measure the change in state mindfulness because there was little room for change. Individuals with higher dispositional mindfulness are already able to focus on the present moment and experience higher mindfulness states before beginning the intervention. Mindfulness states are expected to increase following an intervention (Burke, 
This is an Accepted Manuscript of an article published by Taylor \& Francis in 'The Journal of Educational Research' on 2018-05-08, available online:

https://www.tandfonline.com/10.1080/00220671.2018.1448749.

2010). In this study, there was a significant increase in mindfulness states following the coloring activities; however, this increase was only found for participants who did not report the highest preintervention state mindfulness scores, and consequently, they did not report the highest dispositional mindfulness scores either. As such, participants' dispositional mindfulness can be influencing their ability to experience mindfulness states.

These findings demonstrate that participants with higher dispositional mindfulness are already able to experience mindfulness states without an intervention; therefore, the students with lower reports of dispositional mindfulness are primarily the students reporting benefits following the mindfulness activity. If participants with higher dispositional mindfulness are reporting high mindfulness states before a mindfulness-based intervention, it is important to consider whether mindfulness activities or interventions for these students are worth including in the classroom. Alternatively, an examination of specific methods of assessing enhancing and/or deepening of mindfulness states would help determine if there is a mindfulness benefit of these activities for individuals who are generally mindful day to day.

It is also possible that the students who reported higher dispositional do so as a result of having engaged in other school-based or home mindfulness activities such as yoga and breathing activities (we are aware that student yoga was offered as an optional activity in the schools). As such, the nature of this particular mindfulness-based activity might not have elicited mindfulness in the same way that their regular practice would have. It is possible that art making mindfulness activities are more effective in eliciting mindfulness in those who do not have experience with mindfulness compared with those who do have experience with mindfulness.

\section{Limitations}


This is an Accepted Manuscript of an article published by Taylor \& Francis in 'The Journal of Educational Research' on 2018-05-08, available online:

https://www.tandfonline.com/10.1080/00220671.2018.1448749.

Despite these findings, there are several limitations to be considered. First, building on Carsley et al.'s (2015) initial finding, the definition of a mindfulness-based art activity still remains a topic of discussion. If both groups are reporting equivalent benefits following the coloring activities, educators may be able to provide students with whichever activity is most easily accessible (e.g., free coloring), and the mandala no longer becomes a requirement for a mindfulness art activity. Second, participants who did not agree to participate were not asked to return the forms; therefore, it was not possible to perform analyses to compare the students who agreed to participate versus those who did not agree/provide parent consent. It would be interesting to assess if there were any differences between these two groups of students. Furthermore, given that the participants were predominantly Caucasian and English speaking, and from middle- and upper-class families, an examination of a more diverse sample in future studies would allow for greater generalizability of the findings. Third, a limitation in the present study is the possibility that the decreases in test anxiety observed pre and post across conditions were due to the completion of the scale twice in a short time. Future research is needed with a time-lapse comparison condition to examine this possibility. Furthermore, students' test anxiety scores were generally low, which may limit the generalizability of the present findings to loweranxiety samples.

Fourth, to assess test anxiety, students were told that they would be given a test, and their state of anxiety pre- and post-intervention was assessed. This procedure was chosen due to the lack of state test anxiety measures; current measures of test anxiety assess traits rather than states, which would not be appropriate in the present situation. The creation and inclusion of a measure of test anxiety states would help accurately address states of test anxiety in future test anxiety studies. Finally, the ceiling effect that transpired from the preintervention state 
This is an Accepted Manuscript of an article published by Taylor \& Francis in 'The Journal of Educational Research' on 2018-05-08, available online:

https://www.tandfonline.com/10.1080/00220671.2018.1448749.

mindfulness measure did not allow for an accurate representation of the role of dispositional mindfulness in eliciting a change in state mindfulness pre- and post-intervention. More research is required on the relation between dispositional mindfulness and state mindfulness following an intervention to determine how to best assess these two variables. Furthermore, an examination of how to measure "enhancing" or "deepening of" mindfulness states for individuals with higher dispositional mindfulness is required to assess if these participants can still benefit from mindfulness interventions.

\section{Conclusion}

Despite the limitations, the present study is an important further contribution to our understanding of the relative benefits of mindfulness-based coloring activities versus free coloring activities in schools. Given that both coloring activities appear to be associated with decreases in test anxiety and increases in mindfulness pre- and post-intervention, educators should consider incorporating free draw/coloring activities in their classrooms for students. Although structured coloring of mandalas has been suggested to be a mindfulness-based art activity for test anxiety throughout the media, free drawing and coloring may well provide the same benefits; therefore, educators can include free coloring activities within their classroomswhich are easily accessible — before a test for students who may experience test anxiety.

The current findings suggest a clear direction for future research. In addition to further investigating potential explanations for why students with high dispositional mindfulness are not reporting changes in mindfulness states, it would also be helpful to determine whether there is a difference in other developmental periods. Specifically, an examination of the effectiveness of 
This is an Accepted Manuscript of an article published by Taylor \& Francis in 'The Journal of Educational Research' on 2018-05-08, available online:

https://www.tandfonline.com/10.1080/00220671.2018.1448749.

this activity in an adolescent sample is required, as adolescence represents a developmental period in which test anxiety is prevalent, and individual dispositions continue to be developed.

\section{References}

Abbott, K. A., Shanahan, M. J., \& Neufeld, R. W. J. (2013). Artistic tasks outperform nonartistic tasks for stress reduction. Art Therapy, 30, 71-78.

Barrett, C. A. (2015). Adult coloring books: Patterns for stress relief. Phi Kappa Phi Forum, 95(4), 27.

Beauchemin, J., Hutchins, T. L., \& Patterson, F. (2008). Mindfulness meditation may lessen 
This is an Accepted Manuscript of an article published by Taylor \& Francis in 'The Journal of Educational Research' on 2018-05-08, available online:

https://www.tandfonline.com/10.1080/00220671.2018.1448749.

anxiety, promote social skills, and improve academic performance among adolescents with learning disabilities. Complementary Health Practice Review, 13(34), 34-45. doi:

$10.1177 / 1533210107311624$

Beckwith, P. (2014). Mindfulness and mandalas: Alternative therapeutic techniques for AOD adolescents. Capital University's Undergraduate Research Journal. Retrieved from https://pdfs.semanticscholar.org/ 89c5/da53c284e2d570b6650d09e577cb37874510.pdf

Biegel, G. M., Brown, K. W., Shapiro, S. L., \& Schubert, C. M. (2009). Mindfulness-based stress reduction for the treatment of adolescentpsychiatric outpatients: A randomized clinical trial. Journal of Consult- ing and Clinical Psychology, 77, 855-866. doi: $10.1037 / \mathrm{a} 0016241$

Bishop, D., Bryant, K. S., Giles, S. M., Hansen, W. B., \& Dusenbury, L. (2006). Simplifying the delivery of a prevention program with web- based enhancements. The Journal of Primary Prevention, 27, 433-444. doi: 10.1007/s10935-006-0042-z

Bradley, R., McCraty, R., Atkinson, M., Tomasino, D., Daugherty, D., \& Arguelles, L. (2010). Emotion self-regulation, psychophysiological coherence, and test anxiety: Results from an experiment using electro- physiological measures. Applied Psychophysiology and Biofeedback, 35, 261-283.

Broderick, P. C., \& Metz, S. (2009). Learning to BREATHE: A pilot trial of a mindfulness curriculum for adolescents. Advances in School Mental Health Promotion, 2, 35-46. doi: 10.1080/1754730X.2009.9715696 
This is an Accepted Manuscript of an article published by Taylor \& Francis in 'The Journal of Educational Research' on 2018-05-08, available online:

https://www.tandfonline.com/10.1080/00220671.2018.1448749.

Brown, K. W., \& Ryan, R. M. (2003). The benefits of being present: Mind- fulness and its role in psychological well-being. Journal of Personality and Social Psychology, 84, 822-848. doi: $10.1037 / 0022-3514.84 .4 .822$

Burke, C. A. (2010). Mindfulness-based approaches with children and ado- lescents: A preliminary review of current research in an emergent field. Journal of Child and Family Studies, 19, 133-144. doi: 10.1007/s10926- 009-9282-x

Callahan, M. J. (2016). Mindfulness based art: The SPARKS guide for edu- cators and counselors. Victoria, BC: Freisen Press.

Carsley, D., Heath, N. L., \& Fajnerova, S. (2015). Effectiveness of a class- room mindfulness coloring activity for test anxiety in children. Journal of Applied School Psychology, 31, 239-255. doi: 10.1080/ 15377903.2015.1056925

Chapell, M. S., Blanding, Z. B., Silverstein, M. E., Takahashi, M., Newman, B., Gubi, A., \& McCann, N. (2005). Test anxiety and academic perfor- mance in undergraduate and graduate students. Journal of Educational Psychology, 97, 268-274. doi: 10.1037/00220663.97.2.268

Cunha, M., \& Paiva, M. J. (2012). Text anxiety in adolescents: The role of self-criticism and acceptance and mindfulness skills. The Spanish Journal of Psychology, 15, 533-543. doi: 10.5209/rev_SJOP.2012.v15.n2.38864

Curry, N. A., \& Kasser, T. (2005). Can coloring mandalas reduce anxiety? Art Therapy, 22, 81- 
This is an Accepted Manuscript of an article published by Taylor \& Francis in 'The Journal of Educational Research' on 2018-05-08, available online:

https://www.tandfonline.com/10.1080/00220671.2018.1448749.

85.

Dan, O., \& Raz, S. (2015). The relationships among ADHD, self-esteem, and test anxiety in young adults. Journal of Attention Disorders, 19, 231-239. doi:

$10.1177 / 1087054712454571$

Ergene, T. (2003). Effective interventions on test anxiety reduction: A meta-analysis. School Psychology International, 24, 313-328.

Eum, K., \& Rice, K. G. (2011). Test anxiety, perfectionism, goal orientation, and academic performance. Anxiety, Stress, \& Coping, 24, 167-178. doi:10.1080/10615806.2010.488723

Fridrici, M., \& Lohaus, A. (2009). Stress-prevention in secondary schools: Online-versus faceto-face-training. Health Education, 109, 299-313.

Greco, L. A., Baer, R. A., \& Smith, G. T. (2011). Assessing mindfulness in children and adolescents: Development and validation of the child and adolescent mindfulness measure (CAMM). Psychological Assessment, 23, 606-614. doi: 10.1037/a0022819

Greenberg, M. T., \& Harris, A. R. (2012). Nurturing mindfulness in chil- dren and youth: Current state of research. Child Development Perspec- tives, 6, 161-166. doi: 10.1111/j.1750-8606.2011.00215.x

Gregor, A. (2005). Examination anxiety: Live with it, control it or make it work for you? School Psychology International, 26, 617-635. 
This is an Accepted Manuscript of an article published by Taylor \& Francis in 'The Journal of Educational Research' on 2018-05-08, available online:

https://www.tandfonline.com/10.1080/00220671.2018.1448749.

Hanlon, H., Thatcher, R., \& Cline, M. (2000). Gender differences in the development of EEG coherence in normal children. Developmental Neuropsychology, 16, 479-506.

Hembree, R. (1988). Correlates, causes, effects, and treatment of test anxi- ety. Review of Educational Research, 58, 47-77.

Henderson, P., Rosen, D., \& Mascaro, N. (2007). Empirical study on the healing nature of mandalas. Psychology of Aesthetics, Creativity, and the Arts, 1, 148-154.

Kabat-Zinn, J. (2003). Mindfulness-based interventions in context: Past, present, and future. Clinical Psychology: Science and Practice, 10, 144- 156. doi: 10.1093/clipsy/bpg016

Kail, R. V., \& Cavanaugh, J. C. (2015). Human development: A life-span View (7th ed.). Boston, MA: Cengage Learning.

Kiken, L. G., Garland, E. L., Bluth, K., Palsson, O. S., \& Gaylord, S. A. (2015). From a state to a trait: Trajectories of state mindfulness in meditation during intervention predict changes in trait mindfulness. Personality and Individual Differences, 81, 41-46. doi: 10.1016/j. paid.2014.12.044

King, N. J., Mietz, A., Tinney, L., \& Ollendick, T. H. (1995). Psychopathol- ogy and cognition in adolescents experiencing severe test anxiety. Jour- nal of Clinical Child Psychology, 24, 49-54. doi:10.1207/s15374424jccp2401_6

Larson, H., Ramahi, M., Conn, S., Estes, L., \& Ghibellini, A. (2010). Reduc- ing test anxiety 
This is an Accepted Manuscript of an article published by Taylor \& Francis in 'The Journal of Educational Research' on 2018-05-08, available online:

https://www.tandfonline.com/10.1080/00220671.2018.1448749.

among third grade students through the implementa- tion of relaxation techniques. Journal of School Counseling, 8, 1-19.

LeBeau, R. T., Glenn, D., Liao, B., Wittchen, H., Beesdo-Baum, K., Ollen- dick, T., \& Craske, M. G. (2010). Specific phobia: A review of DSM-IV specific phobia and preliminary recommendations for DSM-V. Depres- sion and Anxiety, 27, 148-167. doi:10.1002/da.20655

Lohbeck, A., Nitkowski, D., \& Petermann, F. (2016). A control-value the- ory approach: Relationship between academic self-concept, interest, and test anxiety in elementary school children. Child Youth Care Forum, 45, 887-904. doi: 10.1007/s10566-016-9362-1

Lowe, P. A., Grumbein, M. J., \& Raad, J. M. (2011). Examination of the psychometric properties of the Test Anxiety Scale for Elementary Stu- dents (TAS-E) scores. Journal of Psychoeducational Assessment, 29, 503-514. doi:10.1177/0734282910395894

Lowe, P. A., \& Lee, S. W. (2008). Factor structure of the test anxiety inven- tory for children and adolescents (TAICA) scores across gender among students in elementary and secondary school settings. Journal of Psy- choeducational Assessment, 26, 231-246.

Lowe, P. A., Lee, S. W., Witteborg, K. M., Prichard, K. W., Luhr, M. E., Cullinan, C. M., ... Janik, M. (2008). The test anxiety inventory for children and adolescents (TAICA): Examination of the psychometric properties of a new multidimensional measure of test anxiety among elementary and secondary school students. Journal of Psychoeduca- tional Assessment, 26, 215-230. doi: 10.1177/0734282907303760 
This is an Accepted Manuscript of an article published by Taylor \& Francis in 'The Journal of Educational Research' on 2018-05-08, available online:

https://www.tandfonline.com/10.1080/00220671.2018.1448749.

McDonald, A. S. (2001). The prevalence and effects of test anxiety in school children.

Educational Psychology, 21, 89-101. doi: 10.1080/ 01443410020019867

Myers, K., \& Winters, N. C. (2002). Ten-year review of rating scales II: Scales for internalizing disorders. Journal of the American Academy of Child \& Adolescent Psychiatry. 41, 634659.

Napoli, M., Krech, P. R., \& Holley, L. C. (2005). Mindfulness training for elementary school students. Journal of Applied School Psychology, 21, 99-125. doi: 10.1300/J370v21n01_05

Nilsson, S., Buchholz, M., \& Thunberg, G. (2012). Assessing children's anxiety using the modified short state-trait anxiety inventory and talk- ing mats: A pilot study. Nursing Research and Practice, 2012, 1-7. doi: 10.1155/2012/932570

Pekrun, R. (2000). A social-cognitive, control-value theory of achievement emotions. In J. Heckhausen (Ed.), Motivational psychology of human development: Developing motivation and motivating development (pp. 143-164). New York, NY: Elsevier.

Segool, N., Carlson, J., Goforth, A., Von der Embse, N., \& Barterian, J. (2013). Heightened test anxiety among young children: Elementary school students' anxious responses to highstakes testing. Psychology in the Schools, 50, 489-499. doi:10.1002/pits.21689

Shapiro, S. L., Brown, K. W., \& Biegel, G. M. (2007). Teaching self-care to caregivers: Effects 
This is an Accepted Manuscript of an article published by Taylor \& Francis in 'The Journal of Educational Research' on 2018-05-08, available online:

https://www.tandfonline.com/10.1080/00220671.2018.1448749.

of mindfulness-based stress reduction on the mental health of therapists in training. Training and Education in Professional Psychology, 1, 105-115. doi: 10.1037/19313918.1.2.105

Shapiro, S. J., Brown, K. W., Thoresen, C., \& Plante, T. G. (2011). The moderation of mindfulness-based stress reduction effects by trait mind- fulness: Results from a randomized controlled trial. Journal of Clinical Psychology, 67, 267-277. doi: 10.1002/jclp.20761

Shapiro, S. L., Oman, D., Thoresen, C. E., Plante, T. G., \& Flinders, T. (2008). Cultivating mindfulness: Effects on well-being. Journal of Clini- cal Psychology, 64, 840-862. doi: 10.1002/jclp.20491

Shorey, R. C., Anderson, S., Lookatch, S., Morre, T. M., \& Stuart, G. L. (2014). The relation between moment-to-moment mindful attention and anxiety among young adults in substance use treatment. Substance Abuse, 36, 374-379. doi: $10.1080 / 08897077.2014 .935841$

Spielberger, C. D. (1973). Manual for the state-trait anxiety inventory for children. Palo Alto, CA: Consulting Psychologists Press.

Swanson, S., \& Howell, C. (1996). Test anxiety in adolescents with learning disabilities and behavior disorders. Exceptional Children, 62, 389-397.

Tabachnick, B. G., \& Fidell, L. S. (2007). Using multivariate statistics, 5th edition. Boston, MA: 
This is an Accepted Manuscript of an article published by Taylor \& Francis in 'The Journal of Educational Research' on 2018-05-08, available online:

https://www.tandfonline.com/10.1080/00220671.2018.1448749.

Pearson Education.

Tan, L. B. G., \& Martin, G. (2012). Mind full or mindful: A report on mindful- ness and psychological health in healthy adolescents. International Journal of Adolescence and Youth, 1-11. doi: 10.1080/02673843.2012.709174

Tobias, S. (1979). Anxiety research in educational psychology. Journal of Educational Psychology, 71, 573-582.

Van der Vennet, R., \& Serice, S. (2012). Can coloring mandalas reduce anxiety? A replication study. Art Therapy, 29, 87-92.

Von der Embse, N., Barterian, J., \& Segool, N. (2013). Test anxiety inter- ventions for children and adolescents: A systematic review of treatment studies from 2000-2010. Psychology in the Schools, 50, 57-71. doi: 10.1002/pits.21660

Weems, C. F., Scott, B. G., Taylor, L. K., Cannon, M. F., Romano, D. M., Perry, A. M., \& Triplett, V. (2010). Test anxiety prevention and inter- vention programs in schools: Program development and rationale. School Mental Health, 2, 62-71. doi:10.1007/s12310-010-9032-7

Weems, C. F., Taylor, L., Costa, N., Marks, A., Romano, D., Verrett, S., \& Brown, D. M. (2009). Effect of a school-based test anxiety intervention in ethnic minority youth exposed to Hurricane Katrina. Journal of Applied Developmental Psychology, 30, 218226. 
This is an Accepted Manuscript of an article published by Taylor \& Francis in 'The Journal of Educational Research' on 2018-05-08, available online:

https://www.tandfonline.com/10.1080/00220671.2018.1448749.

Whitaker Sena, D. J., Lowe, P. A., \& Lee, S. W. (2007). Significant predic- tors of test anxiety among students with and without learning disabil- ities. Journal of Learning Disabilities, 40, 360-376.

Wilkinson, G. S., \& Robertson, G. J. (2006). WRAT-4: Wide range achieve- ment test. Bloomington, MN: Pearson

Wren, D. G., \& Benson, J. (2004). Measuring test anxiety in children: Scale development and internal construct validation. Anxiety, Stress and Coping, 17, 227-240. doi: 10.1080/ 10615800412331292606

Yahav, R., \& Cohen, M. (2008). Evaluation of a cognitive-behavioral inter- vention for adolescents. International Journal of Stress Management, 15, 173-188.

Zenner, C., Herrnleben-Kurz, S., \& Walach, H. (2015). Mindfulness-based interventions in schools - a systematic review and meta-analysis. Fron- tiers in Psychology, 5, 603. doi: 10.3389/fpsyg.2014.00603 
This is an Accepted Manuscript of an article published by Taylor \& Francis in 'The Journal of Educational Research' on 2018-05-08, available online:

https://www.tandfonline.com/10.1080/00220671.2018.1448749.

Tables and Figures

Table 1. Demographic information and pre-intervention test anxiety and state mindfulness scores across participant group.

\begin{tabular}{|l|c|c|c|c|l|}
\hline & \multicolumn{2}{|c|}{ Mindful group } & \multicolumn{2}{c|}{ Free group } & \\
\hline \multicolumn{1}{|c|}{ Variable } & M & SD & M & SD & Significance test \\
\hline Age & 10.42 & 0.82 & 10.36 & 0.93 & $\mathrm{t}(150)=-0.46, \mathrm{p}=.65$ \\
\hline Test anxiety & 27.7 & 4.56 & 27.92 & 4.85 & $\mathrm{t}(150)=0.29, \mathrm{p}=.77$ \\
\hline $\begin{array}{l}\text { State } \\
\text { mindfulness }\end{array}$ & 5.01 & 0.9 & 5.01 & 0.97 & $\mathrm{t}(150)=0.04, \mathrm{p}=.97$ \\
\hline
\end{tabular}

Table 2. Repeated measures multivariate analysis of variance and post hoc analyses for the effects of test anxiety and state mindfulness pre- and postcoloring intervention.

\begin{tabular}{|c|c|c|c|}
\hline \multicolumn{1}{|c|}{ Effect } & Wilk's $\boldsymbol{\lambda}$ & F & Partial $\boldsymbol{\eta} \mathbf{2}$ \\
\hline Time & 0.839 & $28.41^{* * *}$ & 0.161 \\
\hline
\end{tabular}


This is an Accepted Manuscript of an article published by Taylor \& Francis in 'The Journal of Educational Research' on 2018-05-08, available online:

https://www.tandfonline.com/10.1080/00220671.2018.1448749.

\begin{tabular}{|l|l|l|l|}
\hline Time $\mathrm{x}$ Test & 0.813 & $34.07 * * *$ & 0.187 \\
\hline Test anxiety & 0.822 & $32.07 * * *$ & 0.178 \\
\hline State mindfulness & 0.916 & $13.56 * * *$ & 0.084 \\
\hline
\end{tabular}

Table 3. Means and standard deviations for test anxiety and state mindfulness levels in the mindful and free coloring groups.

\begin{tabular}{|c|c|c|c|c|c|c|c|c|c|}
\hline \multirow[b]{2}{*}{ Group } & \multirow[b]{2}{*}{$\mathbf{n}$} & \multirow[b]{2}{*}{$\mathbf{M}$} & \multicolumn{2}{|c|}{$\begin{array}{l}\text { Test anxiety } \\
\text { (pre) }\end{array}$} & \multicolumn{2}{|c|}{$\begin{array}{l}\text { Test anxiety } \\
\text { (post) }\end{array}$} & \multicolumn{2}{|c|}{$\begin{array}{l}\text { State } \\
\text { mindfulness } \\
\text { (pre) }\end{array}$} & \multirow{2}{*}{$\begin{array}{l}\begin{array}{l}\text { State } \\
\text { mindfulnes } \\
\text { s (post) }\end{array} \\
\text { SD } \\
\end{array}$} \\
\hline & & & SD & $\mathbf{M}$ & SD & $\mathbf{M}$ & SD & $\mathbf{M}$ & \\
\hline Mindful & 76 & 27.7 & 4.56 & 25.96 & 5.46 & 5.01 & 0.90 & 5.21 & 0.80 \\
\hline Free & 76 & 27.92 & 4.85 & 25.82 & 5.13 & 5.01 & 0.97 & 5.22 & 0.81 \\
\hline
\end{tabular}

Table 4. Correlations between dispositional mindfulness, gender, and pre- and postintervention changes in state mindfulness.

\begin{tabular}{|l|l|l|l|l|}
\hline & & 1 & 2 & 3 \\
\hline 1. Dispositional Mindfulness & $\mathrm{r}$ & 1 & & \\
\hline 2. Gender & $\mathrm{r}$ & 0.05 & 1 & \\
\hline & $\mathrm{n}$ & 152 & & \\
\hline $\begin{array}{l}\text { 3. Pre- and postintervention state mindfulness } \\
\text { change }\end{array}$ & $\mathrm{r}$ & $-.21^{* *}$ & 0.08 & 1 \\
\hline & $\mathrm{n}$ & 152 & 152 & \\
\hline
\end{tabular}

Figure 1. Correlation between dispositional mindfulness and state mindfulness scores precoloring activity. 
This is an Accepted Manuscript of an article published by Taylor \& Francis in 'The Journal of Educational Research' on 2018-05-08, available online:

https://www.tandfonline.com/10.1080/00220671.2018.1448749.

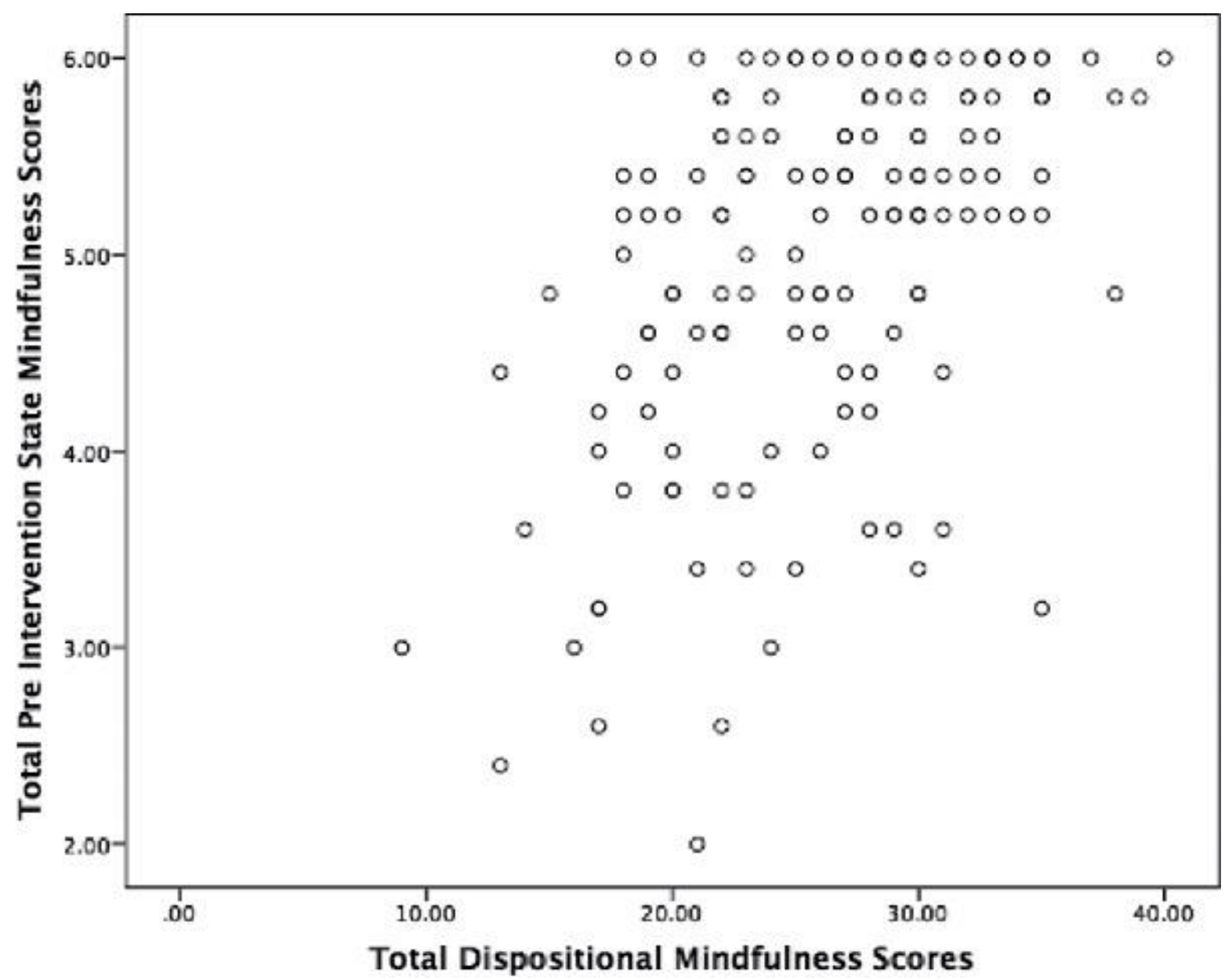

